\title{
Development of $\beta$-cyclodextrin-based hydrogel microparticles for solubility enhancement of rosuvastatin: an in vitro and in vivo evaluation
}

\author{
This article was published in the following Dove Press journal: \\ Drug Design, Development and Therapy \\ 24 October 2017 \\ Number of times this article has been viewed
}

\author{
Rai Muhammad Sarfraz' \\ Mahmood Ahmad ${ }^{2}$ \\ Asif Mahmood ${ }^{3}$ \\ Muhammad Rouf Akram' \\ Asad Abrar ${ }^{2}$ \\ 'Faculty of Pharmacy, University \\ of Sargodha, Sargodha, ${ }^{2}$ Faculty of \\ Pharmacy and Alternative Medicines, \\ The Islamia University of Bahawalpur, \\ Bahawalpur, ${ }^{3}$ Institute of Pharmacy, \\ Physiology and Pharmacology, \\ University of Agriculture Faisalabad, \\ Faisalabad, Pakistan
}

\begin{abstract}
The aim of this study was to enhance the solubility of rosuvastatin (RST) calcium by developing $\beta$-cyclodextrin-g-poly(2-acrylamido-2-methylpropane sulfonic acid [AMPS]) hydrogel microparticles through aqueous free-radical polymerization technique. Prepared hydrogel microparticles were characterized for percent entrapment efficiency, solubility studies, Fourier transform infrared spectroscopy, differential scanning calorimetry, thermal gravimetric analysis, powder X-ray diffraction, scanning electron microscopy, zeta size and potential, swelling and release studies. Formulations (HS1-HS9) have shown entrapment efficiency between $83.50 \% \pm 0.30 \%$ and $88.50 \% \pm 0.25 \%$, and optimum release was offered by formulation HS7 at both pH levels, ie, $1.2(89 \%)$ and 7.4 (92\%). The majority of microparticles had a particle size of less than $500 \mu \mathrm{m}$ and zeta potential of $-37 \mathrm{mV}$. Similarly, optimum solubility, ie, 10.66-fold, was determined at $\mathrm{pH} 6.8$ as compared to pure RST calcium, ie, 7.30-fold. In vivo studies on fabricated hydrogel microparticulate system in comparison to pure drug were carried out, and better results regarding pharmacokinetic parameters were seen in the case of hydrogel microparticles. A potential approach for solubility enhancement of RST calcium and other hydrophobic moieties was successfully developed. Keywords: hydrogel microparticles, rosuvastatin calcium, polymerization, $\beta$-cyclodextrin solubility
\end{abstract}

\section{Introduction}

Newly discovered as well as existing chemical substances have solubility issues due to their lipophilic nature that results in failure of new drug developments. ${ }^{1}$ Drugs administered in low doses should be soluble in water to produce therapeutic effects. ${ }^{2}$ Efforts are continuously made to improve solubility and bioavailability of drugs. ${ }^{3-5}$ Different approaches such as particle size reduction, ${ }^{6-8}$ solubilization by using a surfactant system, ${ }^{9-11}$ hydrosols, interpenetrating networks, ${ }^{12}$ salt formation, ${ }^{13}$ rapid dissolving tablets, ${ }^{14}$ hydrogel microparticles and formation of water-soluble complexes, ie, solid dispersions and inclusion complexes with the aid of hydrophilic polymers, etc., have been tried in the literature successfully. ${ }^{15}$

Hydrogels are cross-linked three-dimensional polymeric networks having ability to imbibe large quantities of water in them while keeping their original geometry. These matrices are extensively employed in pharmaceutical and medical fields due to their special properties, such as excellent swelling, drug loading, degradability, gelling capacity, gel ability and biocompatibility. In the literature, hydrogel microparticles have been utilized for the delivery of insulin and solubility enhancement of acyclovir, methotrexate and other therapeutic agents. ${ }^{16,17}$
Correspondence: Rai Muhammad Sarfraz Faculty of Pharmacy, University of Sargodha, Sargodha, Pakistan Tel +92 3338976189 Email sarfrazrai85@yahoo.com 
These systems are thermally more stable when compared to conventional complex systems, eg, solid dispersions and inclusion complexes, meaning that hydrogel microparticulate systems prevent rapid drug polymer decomplexation and rapid release and improve solubility to a greater extent while having weak interactions, eg, van der Waal forces and hydrogen bonding that promote fast dissociation and release of drug. ${ }^{18,20}$

Rosuvastatin (RST) calcium, a hydroxy-methyl-glutarylcoenzyme A (HMG-CoA) inhibitor, is one of the latest drugs of the statin class. It is widely used for the treatment of familial hyperlipidemia, dyslipidemia, triglyceridemia, atherosclerosis, osteoporosis, benign prostatic hyperplasia and Alzheimer's disease. It belongs to Biopharmaceutics Classification System-II (BCS-II), thereby presenting solubility issues. It is crystalline in nature. It particularly lowers low-density lipoprotein (LDL) level and usually increases the level of high-density lipoproteins (HDLs). It has low bioavailability of $20 \%$ due to its low water solubility and extensive metabolism offered by liver via oxidation, lactonization and glucuronidation. ${ }^{16,19,20}$

$\beta$-Cyclodextrin ( $\beta$-CD) is an acyclic oligosaccharide that has an inner hydrophobic cavity and hydrophilic outer rim. CDs are used in various sectors, ie, agriculture, cosmetics, chemical and pharmaceutical, as they possess innate ability to improve physiochemical properties of water drugs via complexation. They promote solubility, bioavailability and stability of the drugs. $\beta-\mathrm{CD}$ and $\gamma-\mathrm{CD}$ are listed in the generally regarded as safe category of the US Food and Drug Administration (FDA). $\beta$-CD has a prominent place in the pharmaceutical sector as it is economical and easily available and has dimensions of cavity that are suitable for most of the drug candidates. When CDs are polymerized with other polymers or monomers, their ability to enhance solubility and bioavailability increases, ie, hydrogels. ${ }^{21}$ Swelling depends upon the type of monomer used for polymerization, ie, $\mathrm{pH}-$ independent swelling is offered by 2-acrylamido-2-methylpropane sulfonic acid (AMPS) while methacrylic acid offers pH-dependent and ionic-responsive swelling behaviors. ${ }^{22}$

AMPS is a white crystalline powder that is chemically produced from acrylonitrile and isobutylene by Ritter reaction in the presence of powerful sulfonic acid and aqueous media (water). It is freely soluble in water and dimethyl formamide (DMF) and has very limited solubility in polar organic liquids. AMPS-based pharmaceutical drug carriers dissociate over all $\mathrm{pH}$ ranges that give rise to $\mathrm{pH}$-independent swelling. ${ }^{24}$ Moreover, AMPS hydrogels have applications in skin-sensitive electrodes, carriers in biomedical engineering, muscle actuators and in drug delivery. ${ }^{23}$
We present the development of $\beta$-CD- and AMPS-based hydrogel microparticulate system for solubility enhancement of RST calcium. The method could be considered a simple method for the development of hydrogel microparticles by chemical cross-linking with $N, N^{\prime}$-methylene bisacrylamide (MBA) that was tuned and optimized for solubility enhancement purposes. Moreover, to the best of our knowledge, this hydrogel microparticulate system has not been used before for potentiating solubility of RST calcium.

\section{Materials and methods}

RST calcium was obtained as a generous gift from Getz Pharmaceuticals (Karachi, Pakistan). $\beta$-CD (97\%), AMPS (99\%), ammonium persulfate (APS), MBA and methanol were purchased from Sigma-Aldrich Co. (St Louis, MO, USA). Acetonitrile, diethyl ether, absolute ethanol, dichloromethane, chloroform and diethyl acetate were purchased from Sigma-Aldrich Co. The $0.45 \mu \mathrm{m}$-sized membrane filters were purchased from Sartorius (Goettingen, Germany). Highperformance liquid chromatography (HPLC) grade ultrapure water was prepared by Milli- $Q^{\circledR}$ system (EMD Millipore, Billerica, MA, USA).

\section{Synthesis of $\beta$-CD-g-poly(AMPS) hydrogel microparticles}

New polymeric graft was prepared through aqueous freeradical polymerization technique. All the ingredients listed in Table 1 were accurately weighed. APS and MBA were used as initiator and crosslinker, respectively. Both polymer and monomer were separately taken, weighed and poured into beakers containing equal volumes of water. Both the solutions were heated at $50^{\circ} \mathrm{C}$ on a hot plate magnetic stirrer with continuous stirring until the formation of clear solutions. A weighed quantity of APS was poured into $\beta-C D$ solution to initiate polymerization while MBA was added into the monomer

Table I Composition of $\beta$-CD-g-poly(AMPS) hydrogel microparticles

\begin{tabular}{|c|c|c|c|c|}
\hline Code & $\begin{array}{l}\beta-C D \\
(g / 100 g)\end{array}$ & $\begin{array}{l}\text { AMPS } \\
(\mathrm{g} / 100 \mathrm{~g})\end{array}$ & $\begin{array}{l}\text { MBA } \\
(\mathrm{g} / 100 \mathrm{~g})\end{array}$ & $\begin{array}{l}\text { APS } \\
(\mathrm{g} / 100 \mathrm{~g})\end{array}$ \\
\hline$\overline{\mathrm{HSI}}$ & 0.5 & 2 & 0.3 & 0.1 \\
\hline HS2 & I & 2 & 0.3 & 0.1 \\
\hline HS3 & 2 & 2 & 0.3 & 0.1 \\
\hline HS4 & I & 4 & 0.3 & 0.1 \\
\hline HS5 & I & 5 & 0.3 & 0.1 \\
\hline HS6 & I & 6 & 0.3 & 0.1 \\
\hline HS7 & I & 4 & 0.4 & 0.1 \\
\hline HS8 & I & 4 & 0.5 & 0.1 \\
\hline HS9 & I & 4 & 0.6 & 0.1 \\
\hline
\end{tabular}

Abbreviations: AMPS, 2-acrylamido-2-methylpropane sulfonic acid; APS, ammonium persulfate; $\beta$-CD, $\beta$-cyclodextrin; MBA, $N, N^{\prime}$-methylene bisacrylamide. 
(AMPS) solution. Stirring was continued till the clarity of both solutions was attained. Afterward, the monomer solution was added dropwise into the polymer solution. The whole mixture was then sonicated ( $5 \mathrm{~min}$ ) and vortexed ( $3 \mathrm{~min}$ ), and nitrogen gas was purged (20 min) to ensure complete removal of oxygen and proper mixing. This mixture was added into clean and dry labeled glass molds. Test tubes were sealed with aluminum foil, racked in test tube stand and shifted to a digital hot water bath (Memmert, Japan) for $24 \mathrm{~h}$, ie, $55^{\circ} \mathrm{C}$ for $4 \mathrm{~h}, 60^{\circ} \mathrm{C}$ for $8 \mathrm{~h}$, $65^{\circ} \mathrm{C}$ for $8 \mathrm{~h}$ and $70^{\circ} \mathrm{C}$ for $4 \mathrm{~h}$. Upon solidification, test tubes were removed, cooled down to room temperature and broken. Hydrogel disks were cut with a sharp-edged blade into possible small size particles. Particles were soaked in hydroalcohilic solution, ie, methanol and water (50:50), to remove unreacted species. Washing was continued until stable $\mathrm{pH}$ value, ie, 6.5-7, of washing media was attained. Particles were separated from washing media using mesh, and were freeze dried at $-55^{\circ} \mathrm{C}$ for 24 h (Christ Alpha, 1-4LD; Fuzhou Xing Shun Da Refrigeration Facility Project Co., Ltd., Japan). Freeze-dried particles were passed through sieve number 80 to obtain a micrometric size range. These were stored in air-tight containers for further analysis. ${ }^{25}$ Schematic representation of $\beta$-CD-co-poly(AMPS) hydrogel microparticles is shown in Figure 1.

\section{Drug loading}

Diffusion-supported swelling method was adapted for loading of RST in hydrogel microparticles. About 1\% RST solution was prepared in phosphate buffer $(\mathrm{pH}$ 6.8) by dissolving $1 \mathrm{~g}$ of RST in phosphate buffer with a final volume of $100 \mathrm{~mL}$ due to solubility concerns of RST at this $\mathrm{pH}$ value. Lyophilized hydrogel microparticles were weighed precisely and soaked into drug solution for $24 \mathrm{~h}$ at room temperature. Swollen microparticles were separated on screen, and these were flushed with sufficient water to remove surface residues of RST. RST-loaded polymeric microparticles were dried at $40^{\circ} \mathrm{C}$ in a hot air oven (Memmert). ${ }^{26}$

\section{Entrapment efficiency (EE) and product yield}

An extraction method was used to calculate EE and product yield. Prepared microparticles (RST $=20 \mathrm{mg}$ ) were soaked into phosphate buffer of $\mathrm{pH} 6.8(50 \mathrm{~mL})$ to facilitate swelling and drug release. RST determination was performed by developing a calibration curve using a ultraviolet (UV)visible spectrophotometer at $243 \mathrm{~nm}$. EE and product yield were calculated by using the following equations: ${ }^{27}$

$$
\begin{aligned}
& \text { Product yield }=100-\text { Mass loss } \\
& \text { Mass loss }(\%)=\frac{M_{0}-M_{1}}{M_{0}} \times 100
\end{aligned}
$$

where $M_{0}$ is the initial weight and $M_{1}$ is the final weight.

Entrapment efficiency $=$

$$
\frac{\text { Absorbance of sample containing } 20 \mathrm{mg} \mathrm{RST}}{\text { Absorbance of } 20 \mathrm{mg} \text { pure RST }} \times 100
$$

\section{Experimental techniques}

\section{Fourier transform infrared (FTIR) spectroscopy}

Attenuated total reflectance (ATR) technology was used for the determination of functional groups and to record

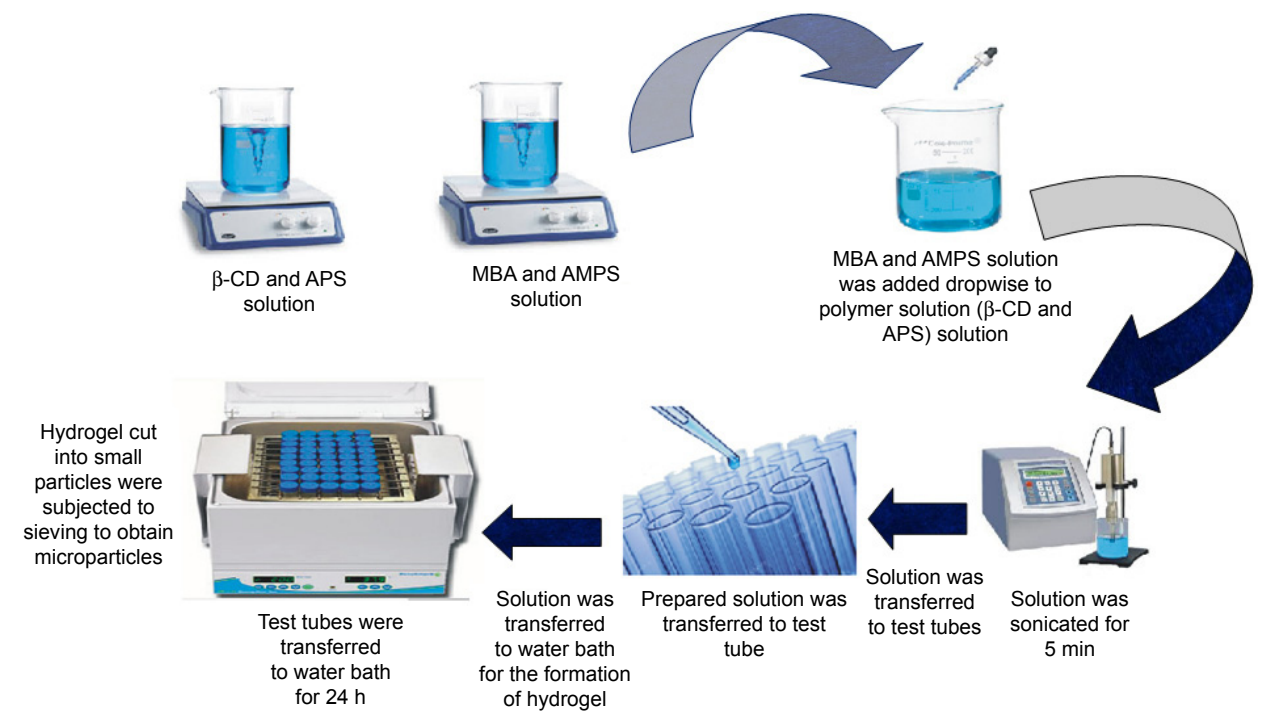

Figure I Schematic representation of hydrogel microparticle synthesis.

Abbreviations: AMPS, 2-acrylamido-2-methylpropane sulfonic acid; APS, ammonium persulfate; $\beta$-CD, $\beta$-cyclodextrin; MBA, N,N'-methylene bisacrylamide. 
infrared (IR) spectra of individual ingredients, ie, APS, MBA, AMPS, RST, physical mixture of $\beta-C D$ and RST, physical mixture of $\beta-C D$, APS, MBA, AMPS, RST and developed hydrogel microparticles. The FTIR spectrophotometer (Tensor 27; OPUS software) was operated after placing the sample on the crystal point of the instrument between 400 and $4,000 \mathrm{~cm}^{-1} \cdot 28$

\section{Thermal analysis}

To measure heat of fusion, melting point, mass loss with temperature rise and stability studies of $\beta-C D$, AMPS, APS, MBA, physical mixture and prepared hydrogel microparticles, differential scanning calorimetry (DSC) and thermal gravimetric analysis (TGA) studies were performed. Samples were triturated and wrapped in an aluminum pan. Simultaneous thermal analyzer (Q600 TA V8.3 Build 101 Thermal Analysis System; TA instruments, New Castle, DE, USA) was operated at $20^{\circ} \mathrm{C} / \mathrm{min}$ under a stream of nitrogen, in triplicate. ${ }^{28}$

\section{Scanning electron microscopy (SEM)}

SEM is a powerful and reliable tool to investigate morphology of hydrogels and their structure under JEOL Analytical Scanning Electron Microscope (JSM-6490A; JEOL, Tokyo, Japan). Dried microparticles were glued on an aluminum stub with conductive carbon tape, followed by $\sim 300 \AA$ thickness of gold coating under argon atmosphere using a gold sputter coater. Finally, samples were scanned, and photomicrographs were recorded and analyzed. ${ }^{26}$

\section{Powder X-ray diffraction (PXRD) studies}

The nature of the individual ingredients and hydrogel microparticles, ie, crystalline or amorphous, was confirmed on RXD X'pert PRO with software Pan Analytical ${ }^{\circledR}$. Results were obtained in triplicate using a scanning range of $2 \theta=5^{\circ}-65^{\circ}$.

\section{Transmission electron microscopy (TEM)}

Internal morphology and geometry was confirmed by TEM JOEL-2010 microscope at $120 \mathrm{kV}$ using different magnifications. ${ }^{29}$

\section{Zeta size and zeta potential measurements}

Particle size of the resultant particles was determined by using particle size analyzer (Zetasizer Ver System; Malvern Instruments, Malvern, UK). Zeta potential of the fabricated hydrogel microparticles was determined to ensure the stability of the polymeric microparticles. ${ }^{30}$

\section{Dissolution studies}

Dissolution studies were performed in a calibrated sixstation dissolution test apparatus (USP type-2; Pharma Test, Hainburg, Germany) at pH 1.2 and 6.8, respectively. The instrument was operated at $50 \mathrm{rpm}$, while the temperature was kept at $37^{\circ} \mathrm{C} \pm 0.2^{\circ} \mathrm{C}$ throughout the experiment. Hydrogel microparticles were enclosed in empty hard gelatin capsule shells and soaked in each basket. About $5 \mathrm{~mL}$ of samples was withdrawn from center, upper and lower portions of the basket by using a graduated pipette and was replaced with fresh dissolution media at predetermined time intervals. The average amount of drug released from hydrogel microparticles at each sampling time was determined by using a UV-visible spectrophotometer (Pharma Spec 1700; Shimadzu, Kyoto, Japan) at $243 \mathrm{~nm}$.

\section{Empirical calculations}

Release data were inserted into empirical equations (kinetic models) by using drug dissolution solver Excel adds in program. Best fit model was confirmed from $r^{2}$ values, and the mechanism of release followed by hydrogel microparticles was confirmed by the value of " $n$," ie, if $n=0.45$, then the drug diffusion mechanism is Fickian diffusion, and if $0.45<\mathrm{n}<0.89$, then it is non-Fickian or anomalous diffusion. If " $n$ " is equal to 0.89 , then it will be case II transport or typical zero-order release.

Zero-order kinetics:

$$
\mathrm{Q}_{\mathrm{t}}=\mathrm{Q}_{\mathrm{o}}-\mathrm{K}_{\mathrm{o}} \mathrm{t}
$$

First-order kinetics:

$$
\operatorname{Ln} Q_{t}=L_{n} Q_{0}-K_{1} t
$$

Higuchi kinetic model:

$$
Q_{t}=K_{h} t^{\frac{1}{2}}
$$

where $Q_{0}$ is the initial amount of RST in hydrogel microparticles, $Q_{t}$ is the amount of drug released at time " $t$ " and $K_{o}$, $\mathrm{K}_{1}$ and $\mathrm{K}_{\mathrm{h}}$ are the rate constants. To determine the mode of drug release, the initial $60 \%$ drug release values were fitted to Korsmeyer-Peppas model:

$$
\frac{\mathrm{M}_{\mathrm{t}}}{\mathrm{M}_{\infty}}=\mathrm{Kt}^{\mathrm{n}}
$$


where $M_{t} / M_{\infty}$ is the fraction of drug released at time $t, K$ is the drug release rate constant and $\mathrm{n}$ is the release exponent. The $\mathrm{n}$ value is employed for the characterization of different release modes for cylindrical-shaped solid formulations. Drug release exponent (n) and drug release mode are related as: $n=0.45$, Fickian diffusion; $0.45<\mathrm{n}<0.89$, anomalous (non-Fickian) diffusion; $\mathrm{n}=0.89$, case II transport and $\mathrm{n}>0.89$, super case II transport. Dissolution data were evaluated using DDSolver. ${ }^{31}$

\section{Solubility studies}

Solubility studies of pure RST calcium and RST loaded in the microparticulate system were carried out at $\mathrm{pH} 1.2$, pH 6.8 and in deionized water. Hydrogel microparticles were enclosed into screw-capped vials having $1 \mathrm{~mL}$ of buffer media. A thermo shaker incubator (MSC-100, Hangzhou Allsheng Instruments Co., Ltd, Allsheng, China) was used for shaking these vials at $37^{\circ} \mathrm{C} \pm 0.5^{\circ} \mathrm{C}$ at $150 \mathrm{rpm}$ for $72 \mathrm{~h}$. All samples were filtered through $0.45 \mu \mathrm{m}$ membrane filters, diluted with buffer and analyzed for RST on a UV-visible spectrophotometer at $243 \mathrm{~nm}^{32}$

\section{Swelling studies}

Swellability of prepared hydrogel microparticles was determined at $37^{\circ} \mathrm{C}$ by enclosing the known amount of hydrogel microparticles (previously enclosed into empty tea bags) in $100 \mathrm{~mL} 0.5 \mathrm{M}$ buffer solutions of $\mathrm{pH} 1.2$ and 6.8. Tea bags were taken out at predefined time intervals to calculate dynamic swelling and weighed after removing the excess of water by blotting with tissue paper. Swelling studies were continued until constant weight of tea bags was not achieved. Degree of swelling and equilibrium water content were determined using the following equations: ${ }^{33}$

$$
\begin{gathered}
\mathrm{Q}=\frac{\mathrm{Ms}}{\mathrm{Md}} \\
\mathrm{EWC} \%=\frac{\mathrm{Ms}-\mathrm{Md}}{\mathrm{Md}} \times 100
\end{gathered}
$$

where EWC is the equilibrium water content, Ms is the mass of swollen hydrogel microparticles and $\mathrm{Md}$ is the mass of dried hydrogel microparticles.

\section{In vivo studies}

In vivo studies were performed using Agilent 1100 series HPLC system to calculate different pharmacokinetic parameters, ie, $\mathrm{C}_{\max }, \mathrm{T}_{\max }$, area under the curve (AUC), mean residence time (MRT), volume of distribution (Vz), $\mathrm{C}_{\text {last }}$ and $\mathrm{t}_{1 / 2}$ in rabbit plasma. The whole study was reviewed and approved by the
Pharmacy Research Ethics Committee (PREC) of the Islamia University of Bahawalpur (reference no 81-2014/PREC). Moreover, PREC guidelines were followed for the welfare of experimental animals (notification no 81-2014/PREC). PREC guidelines, for conducting the experiments on animals, follow the protocols of the US FDA that are prepared under the International Conference on Harmonisation guidelines.

\section{Study design}

A total of 12 male albino rabbits of average weight $1.5 \pm 0.010 \mathrm{~kg}$ and age 6 months were used for this study. Rabbits were divided into two groups $(n=6)$. All the rabbits were fasted overnight with ad libitum and free access to water during the experiment. One group of animals received a single dose of hydrogel microparticles containing $20 \mathrm{mg}$ of RST calcium while the second group was administered commercially available $20 \mathrm{mg}$ tablets of Rovista manufactured by Getz Pharmaceuticals (Karachi, Pakistan). Hair in the sampling area was removed by using depilatory cream, ie, EU-Cream from the neck area to expose the jugular vein, $3 \mathrm{~h}$ before dose administration. Samples were withdrawn at predetermined time intervals, ie, $0,0.5,1,1.5,2,3,4,8$ and $12 \mathrm{~h}$ from the jugular vein by cleansing the targeted area with methylated spirits, and $3 \mathrm{~mL}$ of blood was collected, using a sterile insulin syringe each time, in EDTA tubes, followed by 5-15 mL Glaxose-D solution. No sign of ailment was seen in any rabbit of either group. Each blood sample was centrifuged (Hitachi Zentrifugen EBA 20, Andreas Hettich GmbH \& Co. KG (Hettich), Tuttlingen, Germany) at 5,000 rpm for $10 \mathrm{~min}$. Plasma was carefully removed and collected in eppendorf tubes. Separated plasma was stored at $-70^{\circ} \mathrm{C}$ in an ultralow freezer (maximum $-86^{\circ} \mathrm{C}$; Sanyo, Japan).

Frozen plasma was taken and allowed to thaw at room temperature. About $1 \mathrm{~mL}$ of plasma was taken in glass centrifuge tubes; $0.2 \mathrm{~mL}$ of perchloric acid (20\%) was used as protein precipitant and $20 \mathrm{~mL}$ of perchloric acid (20\%) was prepared by taking $6.45 \mathrm{~mL}$ of $32.25 \%$ perchloric acid and the volume was made up to $20 \mathrm{~mL}$ with distilled water. After the addition of protein precipitant, tubes were vortexed (Mini shaker; IKA, Wilmington, NC, USA) for 3 min to attain proper mixing. Tubes were subjected to centrifugation at 5,000 rpm for $10 \mathrm{~min}$. The separated layer was removed carefully by using a micropipette and collected in eppendorf tubes. It was filtered, and the volume of $20 \mu \mathrm{L}$ was injected for analysis.

\section{Statistical analysis}

All the results were statistically evaluated by using one-way analysis of variance (ANOVA). 


\section{Results}

\section{Product yield, EE and drug loading}

Results of product yield and EE were within the acceptable limits. All formulations (HS1-HS9) had a product yield of $87.00 \%-90.50 \%$ and EE from $83.50 \%$ to $88.50 \%$. Maximum \%EE was seen in the case of formulation HS3, ie, $88.50 \%$. Moreover, the maximum amount of drug was loaded into formulation HS7, ie, $77 \%$. All the results are summarized in Table 2.

\section{FTIR spectroscopy}

FTIR spectra of pure drug, polymer, monomer and developed hydrogel microparticles were recorded to confirm the development of graft polymer. FTIR spectrum of the physical mixture was also recorded to observe any interaction. Spectra were recorded between 500 and $4,000 \mathrm{~cm}^{-1}$. IR spectrum of RST calcium showed that characteristic peaks were present at $3,337.90,2,968.23$ and $1,435.48 \mathrm{~cm}^{-1}$ corresponding to cyclic amines, $\mathrm{C}-\mathrm{H}$ stretching, $\mathrm{C}=\mathrm{O}$ stretching and $\mathrm{O}-\mathrm{H}$ bending. The spectrum of $\beta-\mathrm{CD}$ had alcoholic $\mathrm{O}-\mathrm{H}$ stretching at 3,292.74 $\mathrm{cm}^{-1}$, methyl and methylene $\mathrm{C}-\mathrm{H}$ stretching vibration at $2,927.62 \mathrm{~cm}^{-1}$ and $\mathrm{C}=\mathrm{O}$ ether stretching vibration at $1,021.63 \mathrm{~cm}^{-1}$. RST calcium was also physically mixed with APS, AMPS and MBA to see any interaction among ingredients. However, results did not reveal any interaction among ingredients when they were physically mixed. The results are shown in Figure 2.

\section{Thermal analysis (DSC and TGA)}

In the DSC thermogram of $\beta-\mathrm{CD}$, two endothermic peaks were seen at $106.89^{\circ} \mathrm{C}$ and $329.46^{\circ} \mathrm{C}$ that correspond to moisture loss and the melting point of $\beta$-CD. Upon complete combustion, an exothermic event was observed at $382.31^{\circ} \mathrm{C}$. RST showed a sharp endothermic peak at $143.71^{\circ} \mathrm{C}$ that was near to the melting point of RST. Variation in melting point

Table 2 EE, product yield and drug loading

\begin{tabular}{llll}
\hline Code & EE (\%) & $\begin{array}{l}\text { Product } \\
\text { yield }\end{array}$ & $\begin{array}{l}\text { Drug } \\
\text { loading (\%) }\end{array}$ \\
\hline HSI & $83.50 \pm 0.30$ & $89.00 \pm 1.30$ & $65 \pm 0.35$ \\
HS2 & $84.60 \pm 1.15$ & $88.90 \pm 0.15$ & $69 \pm 0.50$ \\
HS3 & $88.50 \pm 0.50$ & $90.00 \pm 0.25$ & $73 \pm 1.05$ \\
HS4 & $87.50 \pm 0.25$ & $89.50 \pm 1.15$ & $71 \pm 0.75$ \\
HS5 & $87.50 \pm 0.30$ & $89.10 \pm 0.25$ & $69 \pm 0.65$ \\
HS6 & $88.50 \pm 0.25$ & $87.00 \pm 1.30$ & $74 \pm 0.73$ \\
HS7 & $87.80 \pm 0.25$ & $89.10 \pm 0.50$ & $77 \pm 0.75$ \\
HS8 & $88.40 \pm 0.15$ & $90.50 \pm 0.25$ & $73 \pm 0.43$ \\
HS9 & $86.60 \pm 1.30$ & $88.70 \pm 0.30$ & $68 \pm 0.55$ \\
\hline
\end{tabular}

Note: ${ }^{\text {A} A v e r a g e ~ o f ~ t h r e e ~ d e t e r m i n a t i o n s ; ~} \pm$ standard deviation. Abbreviation: $\mathrm{EE}$, entrapment efficiency.

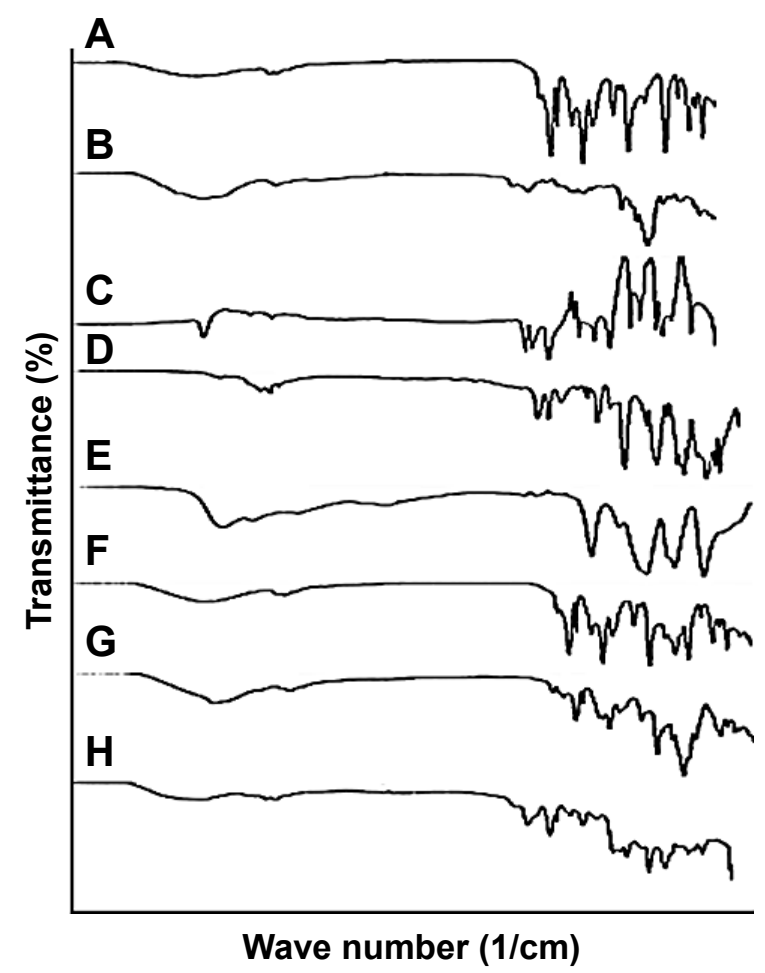

Figure 2 FTIR spectra of (A) RST calcium, (B) $\beta$-cyclodextrin, (C) MBA, (D) AMPS, (E) APS, (F) physical mixture of $\beta-C D$ and RST calcium, (G) physical mixture of RST, APS, AMPS and MBA, $(\mathbf{H})$ hydrogel microparticles.

Abbreviations: AMPS, 2-acrylamido-2-methylpropane sulfonic acid; APS, ammonium persulfate; $\beta$-CD, $\beta$-cyclodextrin; FTIR, Fourier transform infrared; MBA, $N, N^{\prime}$ methylene bisacrylamide; RST, rosuvastatin.

of RST may be due to \%age purity of RST and source of supply. Another endothermic peak at $243.71{ }^{\circ} \mathrm{C}$ was seen upon further increase in temperature, and on final combustion at $378.77^{\circ} \mathrm{C}$ an exothermic event occurred. In the case of the grafted polymeric network, two sharp prominent peaks were observed that indicated that the newly polymerized network was thermally stable.

TGA curve of pure RST calcium presented gradual reduction in mass with the increase in temperature. This loss in mass occurred in three steps, and up to $331.72^{\circ} \mathrm{C}, 47.92 \%$ of mass was lost. TGA thermogram of pure $\beta$-CD presented mass loss of $84.28 \%$ when heated up to $359.21^{\circ} \mathrm{C}$. In the case of the grafted polymeric network, DSC studies showed endothermic peaks at $318.47^{\circ} \mathrm{C}$ and $372.01^{\circ} \mathrm{C}$. TGA of developed hydrogel microparticles offered greater stability to RST as there was only $32.75 \%$ mass loss observed at $372.01^{\circ} \mathrm{C}$. DSC and TGA results are shown in Figure 3.

\section{SEM}

SEM micrographs showed that the majority of polymeric microparticles had irregular geometry and variable diameter from each dimension while few had spherical geometry, as shown in Figure 4. 
A
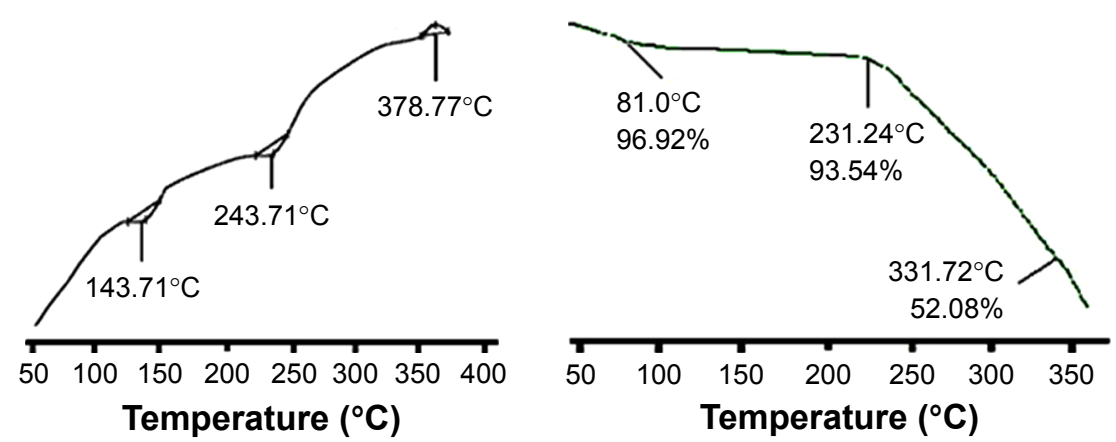

B
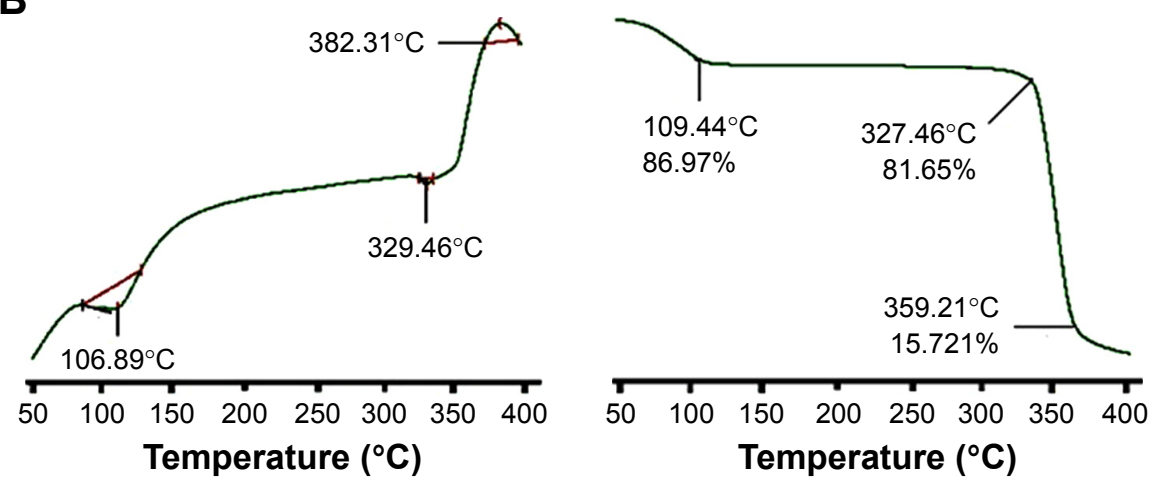

C
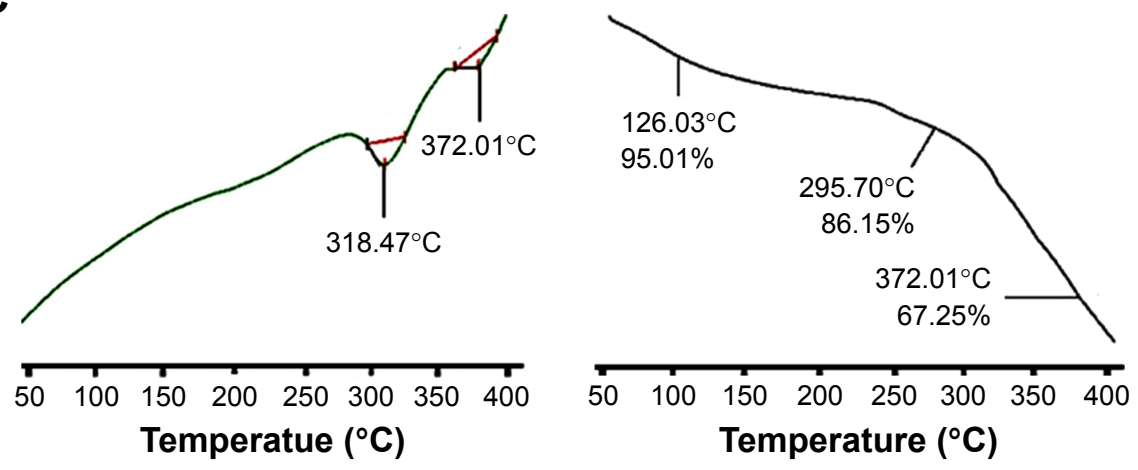

Figure 3 DSC (left) and TGA (right) curves of (A) RST calcium, (B) $\beta$-CD, (C) hydrogel microparticles.

Abbreviations: $\beta-C D, \beta$-cyclodextrin; DSC, differential scanning calorimetry; RST, rosuvastatin; TGA, thermal gravimetric analysis.
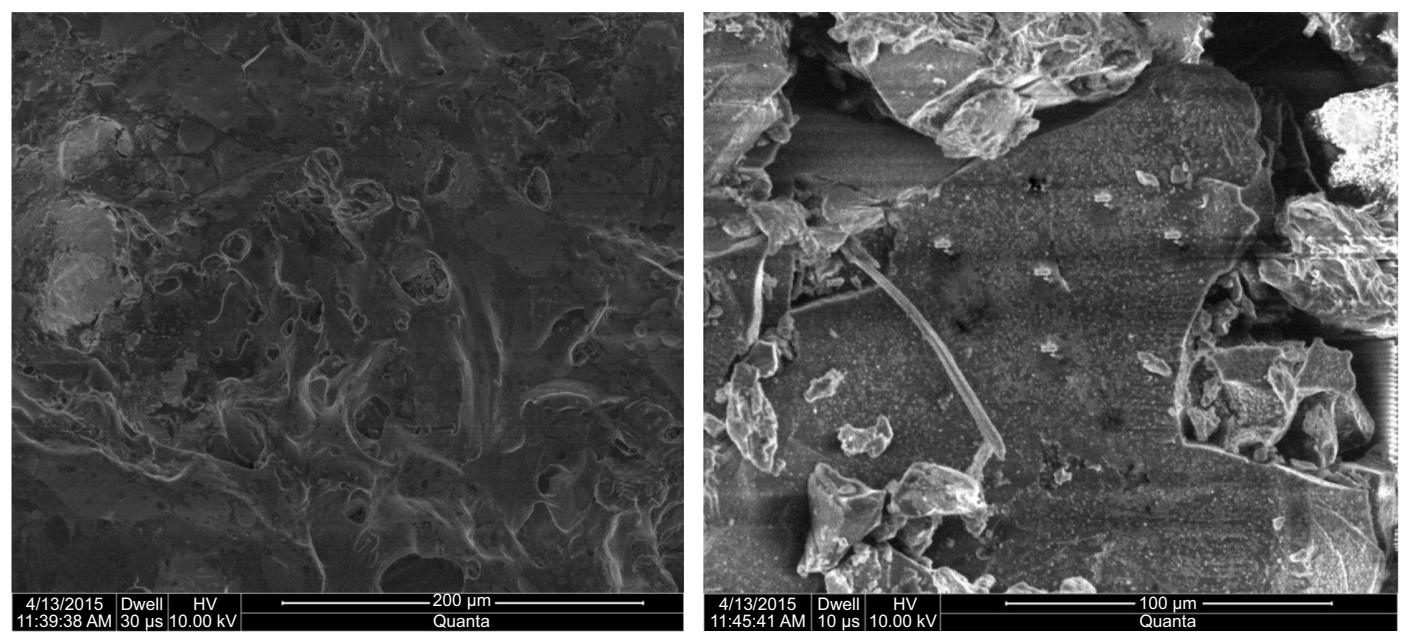

Figure 4 Scanning electron micrographs of lyophilized hydrogel microparticles. 

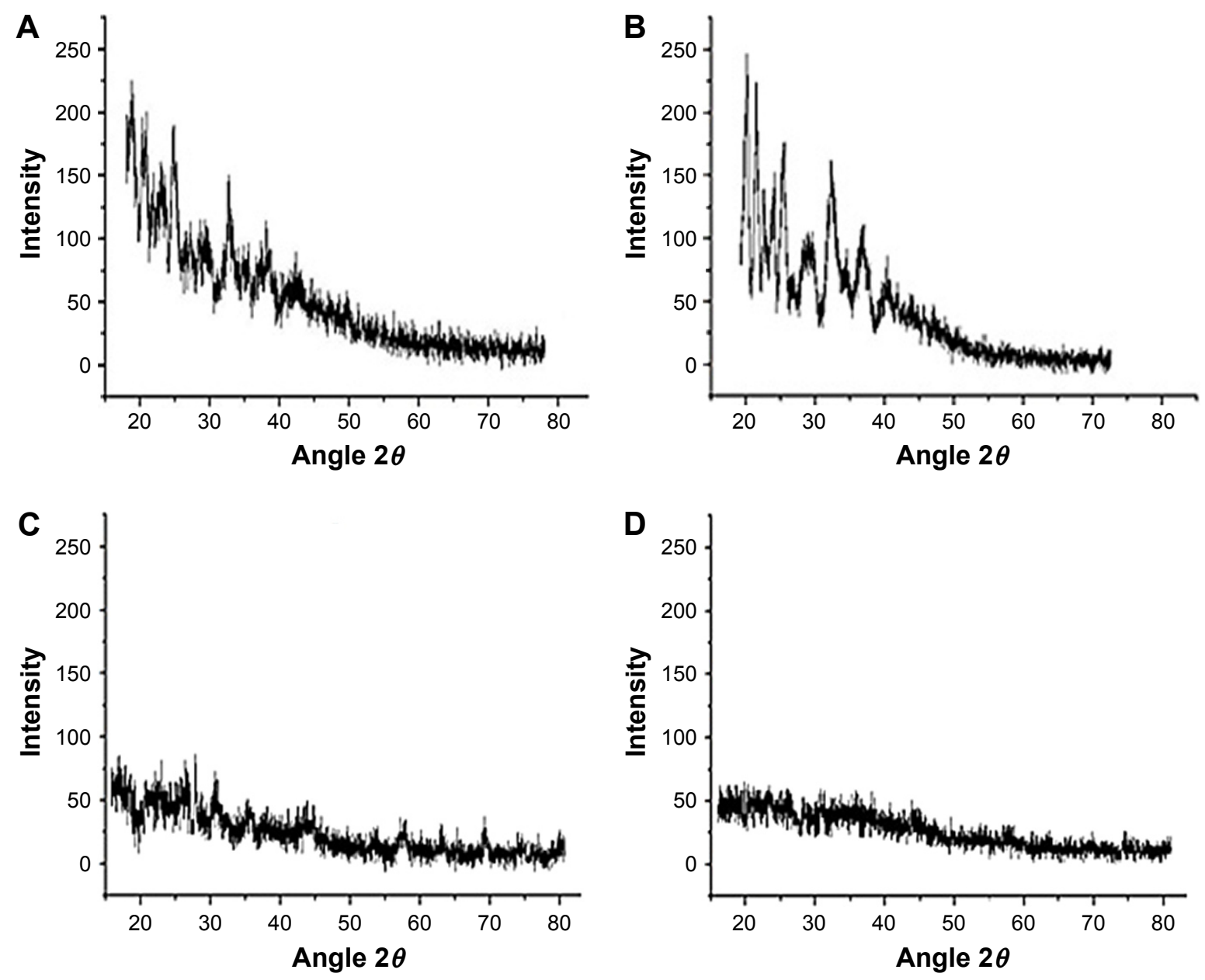

Figure 5 PXRD pattern of (A) RST calcium, (B) $\beta-C D,(\mathbf{C})$ physical mixture and (D) hydrogel microparticles. Abbreviations: $\beta-C D, \beta$-cyclodextrin; PXRD, powder $X$-ray diffraction; RST, rosuvastatin.

\section{PXRD studies}

The presence of sharp peaks at $2 \theta=16.04^{\circ}, 22.45^{\circ}$ and $34.3^{\circ}$ and $2 \theta=20.99^{\circ}, 26.85^{\circ}, 34.63^{\circ}, 40.03^{\circ}$ and 43.85 confirmed the crystalline nature of RST and $\beta-\mathrm{CD}$, respectively, as shown in Figure 5.

\section{TEM}

TEM micrographs of fabricated microparticles from crosssectional area were recorded. Micrographs proved that microparticles had porous surface. RST was transported through these pores and appeared as a whitish mass. All the results are shown in Figure 6.

\section{Zeta size and zeta potential measurements}

Values of the zeta size of formulations were in micron size ranging from 200 to $500 \mu \mathrm{m}$ but the majority of microparticles had a size of $300 \mu \mathrm{m}$, while zeta potential value was near to $-37 \mathrm{mV}$, as shown in Figure 7A and B.

\section{Dissolution studies}

Results of dissolution studies showed that there was a marked difference in the release of drug from hydrogel microparticles when compared with the marketed brand of

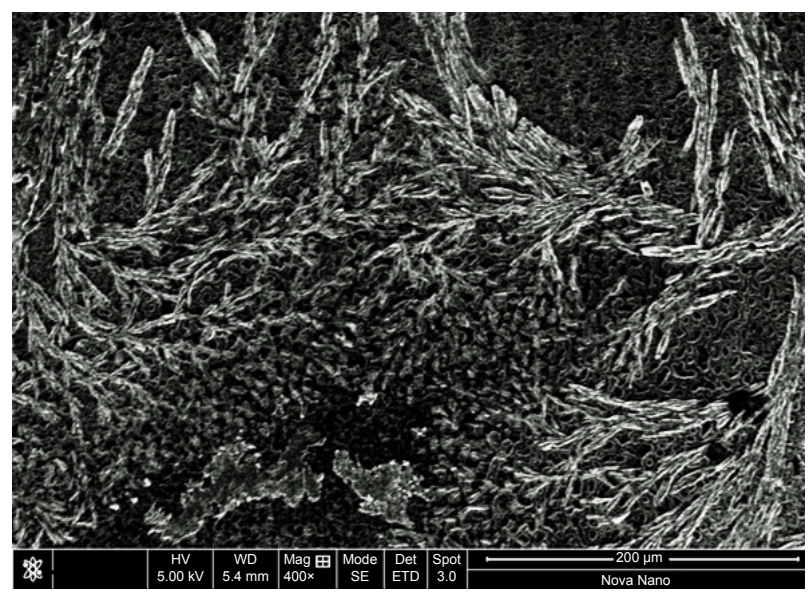

Figure 6 TEM micrograph of lyophilized hydrogel microparticles. Abbreviation: TEM, transmission electron microscopy. 


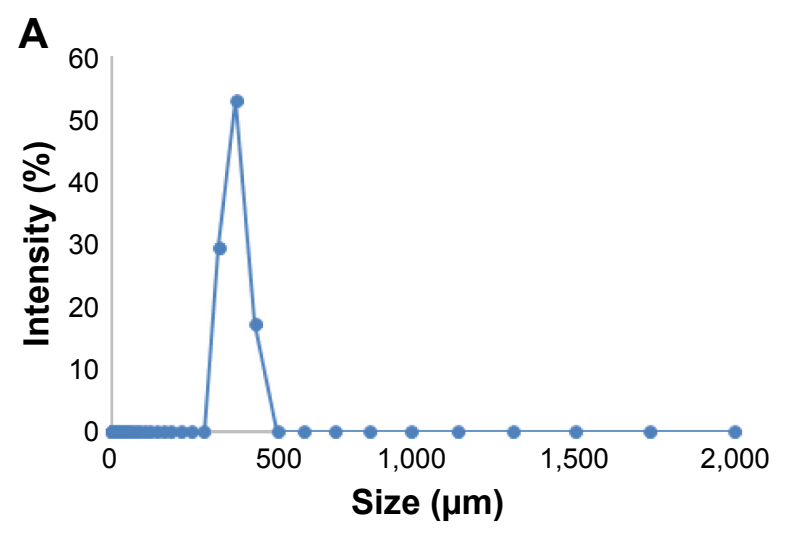

\section{B}

Figure 7 Zeta size and zeta potential.

Notes: (A) Zeta size measurement of hydrogel microparticles. (B) Zeta potential measurements of hydrogel microparticles.

RST, ie, tablet Rovista. Better release results were observed at $\mathrm{pH} 6.8$ as compared to $\mathrm{pH} 1.2$ due to the acidic nature of RST calcium. It is a weak acid and becomes more ionized in basic environment thus more soluble in basic media. From formulation $\mathrm{HS} 7,92 \%$ of drug was released within $1 \mathrm{~h}$ while from RST tablets only $44 \%$ of drug was released in $3 \mathrm{~h}$ at $\mathrm{pH}$ 6.8, as shown in Figure 8A. Slightly less amount of drug was released from hydrogel microparticles at $\mathrm{pH} 1.2$, as shown in Figure 8B, but the optimized formulation was HS7.

\section{Solubility studies}

Solubility of hydrogel microparticles was potentiated at acidic, basic and in distilled water. This was due to $\mathrm{pH}$ independent swelling behavior of AMPS. The solubility of hydrogel microparticles was enhanced up to 7.5 -fold at $\mathrm{pH} 1.2$, while 10.66 -fold solubility was enhanced at $\mathrm{pH} 6.8$. In distilled water, the solubility of RST-loaded hydrogel microparticles was increased up to 7.30 -fold, as shown in Figure 9.

\section{Swelling studies}

Release of drug from hydrogel microparticles is dependent upon swelling behavior. If higher swelling is present within hydrogel microparticles, then more rapid drug will be released. Developed hydrogel microparticles have higher swelling at $\mathrm{pH} 7.4$ as compared to $\mathrm{pH} 1.2$. At $\mathrm{pH} 1.2$, equilibrium swelling percent (ES\%) was between 5.45\% and $76.14 \%$, while at $\mathrm{pH} 7.4 \mathrm{ES} \%$ was between $7.93 \%$ and $84.12 \%$, as shown in Figure 10.

\section{In vivo pharmacokinetic studies}

Different pharmacokinetic parameters such as $\mathrm{C}_{\text {max }}(\mathrm{ng} / \mathrm{mL})$, $\mathrm{T}_{\max }(\mathrm{h}), \mathrm{t}_{1 / 2}(\mathrm{~h}), \mathrm{AUC}_{0-\mathrm{t}}(\mathrm{ng} / \mathrm{mL} \cdot \mathrm{h}), \operatorname{MRT}(\mathrm{h}), \mathrm{C}_{\text {last }}(\mathrm{ng} / \mathrm{mL}$ ) and $\mathrm{T}_{\text {last }}(\mathrm{h})$ were calculated. These pharmacokinetic parameters
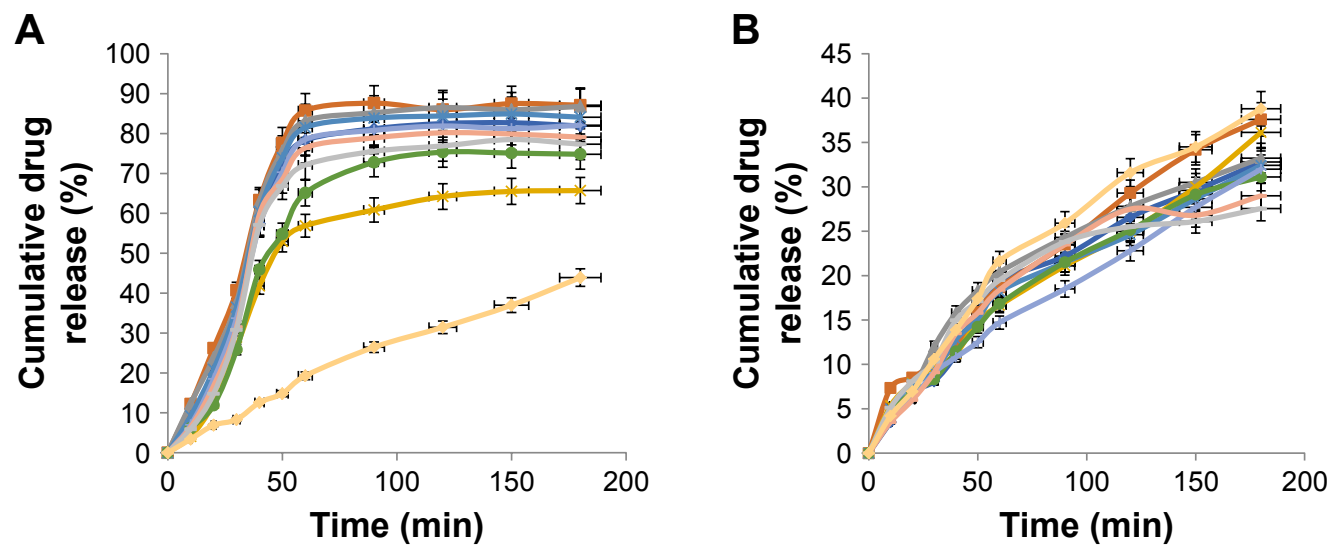

$\rightarrow \mathrm{HS} 1 \rightarrow \mathrm{HS} 2-\mathrm{HS} 3 \multimap \mathrm{HS} 4 \rightarrow \mathrm{HS} 5 \rightarrow \mathrm{HS} 6-\mathrm{HS} 7-\mathrm{HS} 8-\mathrm{HS} 9 \rightarrow \mathrm{RST}$ tablet

Figure 8 In vitro drug release profiles.

Notes: (A) Cumulative\% drug release from hydrogel microparticles and RST tablets at pH 6.8. (B) Cumulative\% drug release from hydrogel microparticles and RST tablets at $\mathrm{pH}$ I.2.

Abbreviation: RST, rosuvastatin. 


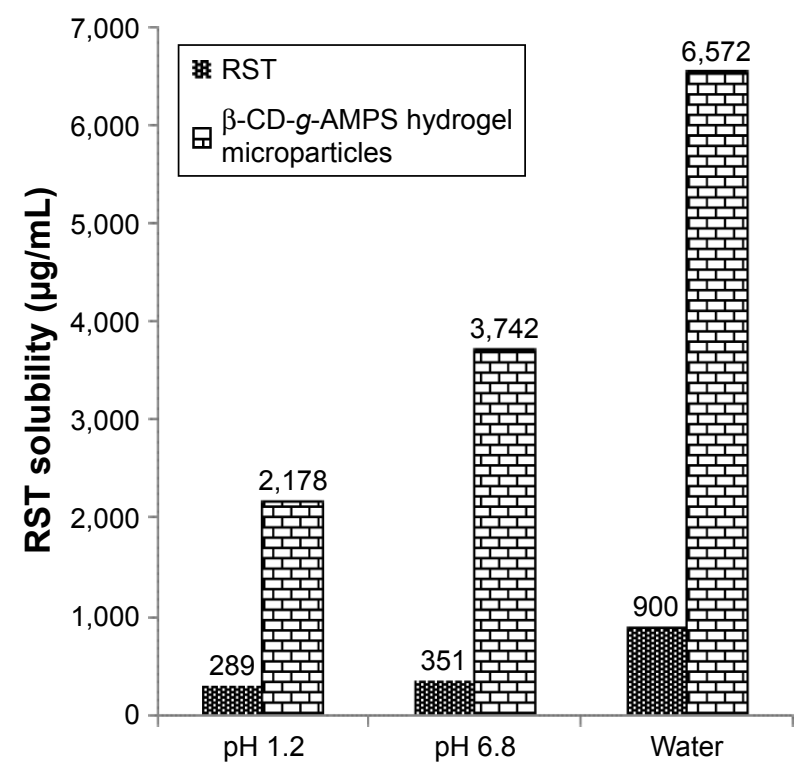

Figure 9 Solubility studies of pure drug and hydrogel microparticles. Abbreviations: AMPS, 2-acrylamido-2-methylpropane sulfonic acid; $\beta-C D, \beta$ cyclodextrin; RST, rosuvastatin.

of RST calcium were analyzed after the administration of hydrogel microparticles and commercially available tablets of RST calcium. Non-compartmental pharmacokinetic analysis was performed using software package kinetica $\mathrm{V}$ 4.4. Peak plasma concentration $\left(\mathrm{C}_{\max }\right)$ and time required to reach peak plasma concentration $\left(\mathrm{T}_{\max }\right)$ were calculated from the visual inspection of plasma concentration-time curves. The area under the plasma concentration-time curve $\left(\mathrm{AUC}_{0-\mathrm{t}}\right)$ was calculated by using trapezoidal rule.

Results of mean plasma concentration after the administration of hydrogel microparticles and commercially available tablets of RST calcium was calculated. Mean values of different pharmacokinetic parameters of RST calcium after oral administration of hydrogel microparticles and

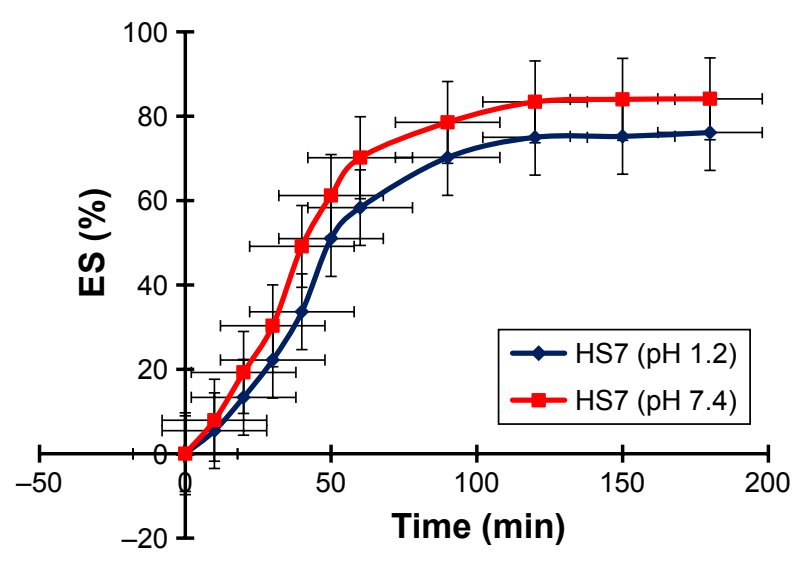

Figure 10 ES\% at $\mathrm{pH} 1.2$ and $\mathrm{pH} 7.4$ (HS7).

Abbreviation: ES\%, equilibrium swelling percent.
Table 3 Mean values of pharmacokinetic parameters

\begin{tabular}{lll}
\hline Parameters & $\begin{array}{l}\text { Hydrogel } \\
\text { microparticles }\end{array}$ & $\begin{array}{l}\text { Commercial } \\
\text { tablet }\end{array}$ \\
\hline $\mathrm{C}_{\text {max }}(\mathrm{ng} / \mathrm{mL})$ & 90.543 & 41.263 \\
$\mathrm{~T}_{\text {max }}(\mathrm{h})$ & 2.00 & 4.00 \\
$\mathrm{AUC}_{0-\mathrm{t}}(\mathrm{ng} / \mathrm{mL} \cdot \mathrm{h})$ & 480.09 & 366.79 \\
$\mathrm{AUC}_{0-\infty}(\mathrm{ng} / \mathrm{mL} \cdot \mathrm{h})$ & 567.26 & $1,200.093789$ \\
$\mathrm{AUMC}_{0-\infty}$ & $3,728.439942$ & $35,029.79044$ \\
$\mathrm{MRT}(\mathrm{h})$ & 6.57 & 29.18 \\
$\mathrm{C}_{\text {last }}(\mathrm{ng} / \mathrm{mL})$ & 10.385 & 28.728 \\
$\mathrm{~T}_{\text {last }}(\mathrm{h})$ & 4.00 & 12.00 \\
$\mathrm{t}_{1 / 2}(\mathrm{~h})$ & 4.20 & 18.80 \\
$\mathrm{Vz}(\mu \mathrm{g} / \mathrm{mL})$ & 8.82581294 & 18.64547677 \\
$\mathrm{Cl}(\mu \mathrm{g} / \mathrm{mL}) / \mathrm{h}$ & 1.454359553 & 0.687446627 \\
\hline
\end{tabular}

Notes: $C_{\max }$, maximum concentration; $T_{\max }$, maximum time; $t_{1 / 2}$, half-life; $V z$, volume of distribution.

Abbreviations: AUC, area under the curve; AUMC, area under the first moment curve; $\mathrm{Cl}$, clearance; MRT, mean residence time.

commercially available tablets of RST calcium are given in Table 3. Pharmacokinetic data were statistically analyzed using one-way ANOVA.

Pharmacokinetic studies also proved the rapid release of drug from hydrogel microparticles compared to commercially available tablets of RST. Values of $\mathrm{C}_{\max }$ were 90 and $41 \mathrm{ng} / \mathrm{mL}$ for hydrogel microparticles and commercially available tablets of RST calcium, respectively, as shown in Figure 11.

\section{Discussion}

$\mathrm{EE}$ is a vital parameter that is used to determine the efficiency of a prepared carrier system to evaluate a suitable dosage regimen. It was noticed that with the increase in polymeric content $\%$ EE was increased from $83.50 \%$ to $88.50 \%$, not up to $100 \%$, because RST transport from the drug solution $(1 \%$ RST solution, ie, $1 \mathrm{~g}$ in buffer solution up to volume $100 \mathrm{~mL}$ )

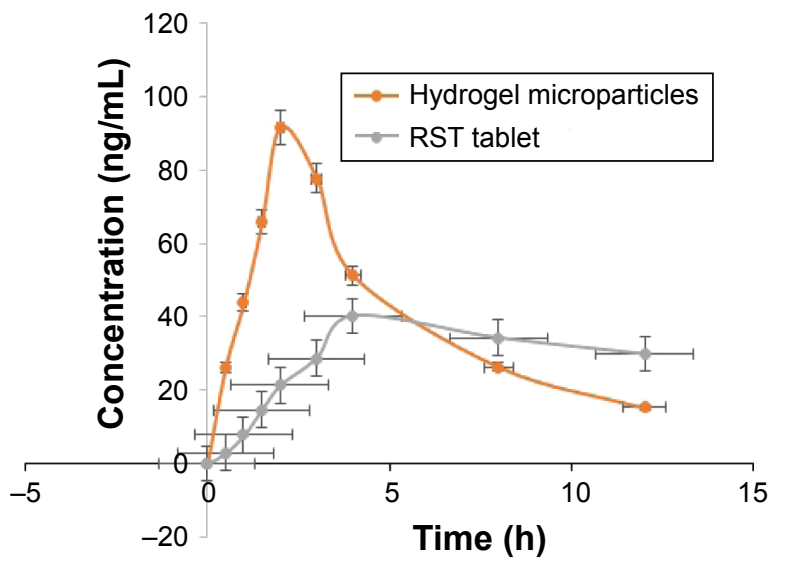

Figure I I Combined plasma profile of RST calcium after the administration of hydrogel microparticles and commercially available RST tablets.

Abbreviation: RST, rosuvastatin. 
was diffusion assisted and during washing of the hydrogel microparticles surface RST was removed. Similarly, product yield was also higher in this formulation due to high polymeric content. High polymeric content offer more channeling and hydrophilic character to developed carrier system leading to more and more penetration of the RST. Our results have justified that the prepared carrier system was suitable for the loading of RST and its accurate delivery at the target site.

FTIR spectra of each participant of hydrogel microparticle formulation (HS1-HS9) were recorded to investigate any possible interaction in formulation component. FTIR spectrum of $\beta$-CD-co-poly(AMPS) cross-linked hydrogel microparticles was entirely different from that of pure drug, ie, RST and polymer, ie, $\beta$-CD. It was evident from the IR spectra of hydrogel microparticles that shifting of characteristic peaks was from 3,337.90 and 2,968.23 $\mathrm{cm}^{-1}$ to $3,306.87$ and $2,930.97 \mathrm{~cm}^{-1}$, respectively. The peak present at $1,438.03 \mathrm{~cm}^{-1}$ was shifted toward higher values of 1,655.91. Shifting, reduction in intensity and broadening of peaks confirmed that there was a new polymeric complex formation. Riekes et $\mathrm{al}^{34}$ prepared complexes of $\beta$-CD with amiodarone for solubility and dissolution improvements. They studied FTIR spectra of individual ingredients. $\beta-C D$ bands were present in the physical mixture while in the case of complexes these bands were absent thus indicating complex formation as proved in our study.

Thermal analysis was performed to check the stability of $\beta$-CD-co-poly(AMPS) hydrogel microparticles. In the case of $\beta$-CD-co-poly(AMPS) hydrogel microparticle thermogram, shifting of endothermic peaks to higher temperatures confirmed that polymer and monomer individual ingredients are cross-linked and a stable hydrogel network in the form of microparticles has been developed successfully. DSC and TGA thermograms have different patterns of thermal stability of $\beta$-CD-co-poly(AMPS) hydrogel microparticles. Cross-linking improves thermal stability as well as provides excellent delivery ability for various drugs. Our results are in good agreement with a previously conducted study by Chen et al, ${ }^{35}$ where they prepared chitosan-based hydrogel beads and concluded that disappearance or shifting of peaks is the indication of complex formation and drugs become more soluble when they form a complex with other hydrophilic moieties.

In SEM photomicrographs, the presence of white spots confirmed that RST was successfully distributed and loaded within the microparticles. Microparticles had porous surfaces that assisted rapid penetration of water and high swelling and ultimately promoted rapid faster release. Borba et $\mathrm{al}^{36}$ prepared microparticles of less water-soluble drug telmisartan. They analyzed morphology and particle size of microparticles. Their results showed that developed microparticles had irregular shapes and variable sizes but in the micrometric range they offered large surface area, fast wetting and, ultimately, more solubility as observed in our SEM results.

$\mathrm{X}$-ray diffraction studies were conducted to confirm the nature of ingredients as well as fabricated crosslinked networks. Presence of peaks in XRD diffractograms of drug and polymer proved crystalline nature due to which these both have solubility issues. While, in the diffractogram of hydrogel microparticles, these characteristic peaks were markedly reduced and fused with each other to ensure the conversion of the crystalline form into the amorphous form with better solubility profile. Thus, the solubility of RST was enhanced in hydrogel microparticles, because amorphous forms are more soluble than crystalline. Similarly, results have been proved in a work conducted by Zhang et al. ${ }^{37}$ They proved the loss of crystalline nature of berberine hydrochloride when processed with $\beta-C D$.

TEM studies revealed that microparticles had porous surface that facilitated rapid uptake of media and swelling and release of the drug from the developed carrier. White appearances confirmed successful loading and distribution of RST. Small size and large surface area lead to dissolution enhancement of RST. These findings agree with the findings of Sinha et al. ${ }^{38}$

All the prepared hydrogel microparticles had size within the micrometric size range that was desired in this work. Zeta potential values near to $-40 \mathrm{mV}$ usually confirm the stability of a particulate system. All the formulations (HS1-HS9) had zeta potential values near to $-40 \mathrm{mV}$, ie, $-37 \mathrm{mV}$ confirmed the stability of the developed hydrogel microparticles. Negative charge imparts repulsion among microparticles and resists aggregation of microparticles. ${ }^{39}$

Maximum release $(92 \%)$ was observed at $\mathrm{pH} 6.8$ by formulation HS7. This was due to the hydrophilic nature of $\beta-C D$, micrometric size range and porous nature confirmed from SEM studies and AMPS contents. As the concentration of AMPS increases, it offers more channeling and promotes release of drug. Various concentrations of AMPS and MBA were studied to optimize the best concentration to enhance dissolution of RST. When $4 \mathrm{~g} / 100 \mathrm{~g}$ of AMPS was used, it produced the best release rate as compared to 2, 5 and $6 \mathrm{~g} / 100 \mathrm{~g}$ of formulation. Similarly, MBA produced the best results when $0.4 \mathrm{~g} / 100 \mathrm{~g}$ was used. The rate and percent release of RST from the cross-linked system is dependent on swelling behavior, composition of copolymeric system, environmental conditions and $\mathrm{pH}$ of dissolution medium. A 
study conducted by Chen et al supported our findings that $\beta-C D$ enhances dissolution profile of BCS-II drugs by complex formation. ${ }^{40}$ Kinetic models were applied on release data to determine the best fit model. Drug release followed firstorder kinetics in the case of hydrogel microparticles while RST tablets followed zero-order kinetics, as given in Table 4. Formulations HS4 and HS7 followed anomalous diffusion of RST, which means that dual mode of drug release was diffusion and erosion based. This was due to the presence of $\beta$-CD hydrogel microparticles that enhanced the release of the drug from the carrier system.

RST calcium is a weak acid. Due to its acidic nature, it has more solubility in basic media as compared to acidic $\mathrm{pH}$. So, it becomes ionized at higher $\mathrm{pH}$ values and therefore more soluble in solutions having high $\mathrm{pH}$. However, AMPS gives more swelling at higher $\mathrm{pH}$ values that have also contributed to more and more uptake of solvent. Moreover, solubility in phosphate buffer solution ( $\mathrm{pH}$ 6.8) was due to the weak acidic nature of RST. These findings confirmed that hydrophilic complexation of RST with $\beta$-CD containing hydrogel microparticles potentiated the solubility of RST. The order in which RST had more solubility was distilled water $>$ phosphate buffer of $\mathrm{pH} 6.8>\mathrm{HCl}$ buffer of $\mathrm{pH}$ 1.2.

All prepared formulations exhibited good swelling behavior. AMPS is a hydrophilic monomer that possesses both ionic and non-ionic functional groups. As the number of ionizable groups $\left(-\mathrm{SO}_{3}\right)$ is enhanced, swelling capacity increases due to the availability of ionizable groups. Previously, Elliott et al also observed the same kind of swelling behavior from AMPS and concluded that AMPS had $\mathrm{pH}$-independent swelling. ${ }^{39}$ In another work, conducted by $A t t a,{ }^{41}$ similar findings for AMPS-based hydrogels were

Table 4 In vitro drug release kinetics of hydrogel microparticles

\begin{tabular}{lllll}
\hline Models & Parameters & HS4 & HS7 & RST tablet \\
\hline Zero-order kinetics & $\mathrm{K}_{0}$ & 0.720 & 0.737 & 0.259 \\
& $\mathrm{R}^{2}$ & 0.7769 & 0.7990 & 0.9573 \\
& $\mathrm{~T}_{25}$ & 34.726 & 33.935 & 89.438 \\
& $\mathrm{~T}_{50}$ & 69.452 & 67.870 & 192.875 \\
& $\mathrm{~T}_{75}$ & 104.178 & 101.805 & 289.313 \\
First-order kinetics & $\mathrm{K}_{1}$ & 0.025 & 0.025 & 0.003 \\
& $\mathrm{R}^{2}$ & 0.9988 & 0.9884 & 0.9682 \\
& $\mathrm{~T}_{25}$ & 11.684 & 11.389 & 89.357 \\
& $\mathrm{~T}_{50}$ & 28.153 & 27.442 & 215.299 \\
& $\mathrm{~T}_{75}$ & 56.305 & 54.883 & 430.598 \\
& $\mathrm{~K}_{\mathrm{H}}$ & 8.286 & 8.459 & 2.744 \\
& $\mathrm{R}^{2}$ & 0.8957 & $0.913 \mathrm{I}$ & 2.744 \\
Kiguchi & $\mathrm{K}_{\mathrm{kp}}$ & 14.148 & 14.154 & 0.600 \\
& $\mathrm{R}^{2}$ & 0.9108 & $0.971 \mathrm{I}$ & 0.9978 \\
& $\mathrm{~N}$ & 0.383 & 0.9265 & 0.827 \\
\hline
\end{tabular}

Abbreviation: RST, rosuvastatin. seen. Polymeric complexes that have higher AMPS content offer more swelling.

From in vivo studies, it was confirmed that there was rapid release of drug from prepared formulations that ultimately improved the bioavailability of the drug in rabbit plasma. Similarly, $\mathrm{AUC}_{0-24}$ was also higher for prepared formulations of hydrogel microparticles. This means that a larger amount of drug was released from prepared formulations due to complex formation with $\beta-\mathrm{CD}$ and the drug became more soluble in gastric media. Results of $\mathrm{C}_{\max }$ and $\mathrm{AUC}_{0-24}$ were significant $(p<0.05)$. Hydrogel microparticles have a value of $\mathrm{T}_{\max } 2 \mathrm{~h}$ while RST tablets have $4 \mathrm{~h}$ which meant that prepared formulations released RST more rapidly as compared to RST tablets. This rapid release of drug was due to more solubility. Elimination half-life $\left(\mathrm{t}_{1 / 2}\right)$ of hydrogel microparticles was $4.20 \mathrm{~h}(p<0.05)$, while commercially available RST tablets had a half-life of $18.80 \mathrm{~h}$. This confirmed that more rapid bioavailability was achieved from hydrogel microparticles as compared to commercial tablets. These results confirmed that the solubility of the drug increased in prepared formulations due to complexation with the carrier system that ultimately enhanced its bioavailability. ${ }^{42}$

\section{Conclusion}

In the current study, $\beta$-CD-g-poly(AMPS) hydrogel microparticles with different ratios of polymer, monomer and cross-linking agent were successfully prepared and tuned for solubility enhancement of RST calcium. Prominent rise in solubility of RST was observed at $\mathrm{pH}$ 6.8. RST release behavior from $\beta$-CD-g-poly(AMPS) hydrogel microparticles was observed and found swelling-dependent release. Slightly higher swelling was seen at $\mathrm{pH}$ 7.4. Pharmacokinetic parameters also confirmed rapid release and excellent bioavailability offered by this developed polymeric carrier system. This system can be utilized for solubility and bioavailability enhancement of other hydrophobic drugs.

\section{Acknowledgment}

The authors are thankful to the Higher Education Commission (HEC) of Pakistan for providing funds in the form of Indigenous Scholarship (Ref no 213-57857-2BM2-135).

\section{Disclosure}

The authors report no conflicts of interest in this work.

\section{References}

1. Perrut M, Jung J, Leboeuf F. Enhancement of dissolution rate of poorly-soluble active ingredients by supercritical fluid processes: part I: micronization of neat particles. Int J Pharm. 2005;288(1):3-10. 
2. Ku MS, Dulin W. A biopharmaceutical classification-based RightFirst-Time formulation approach to reduce human pharmacokinetic variability and project cycle time from First-In-Human to clinical proof of concept. Pharm Dev Technol. 2012;17(3):285-305.

3. Lipinski CA, Lombardo F, Dominy BW, Feeney PJ. Experimental and computational approaches to estimate solubility and permeability in drug discovery and development settings. Adv Drug Deliv Rev. 1997; 23:3-25.

4. Hiroaki KUBO, Osawa T, Takashima K, Mizobe K. Enhancement of oral bioavailability and pharmacological effect of 1-(3, 4-dimethoxyphenyl)-2, 3-bis (methoxycarbonyl)-4-hydroxy-6, 7, 8-trimethoxynaphthalene (TA-7552), a new hypocholesterolemic agent, by micronization in co-ground mixture with D-mannitol. Biol Pharm Bull. 1996;19:741-747.

5. Martis L, Hall NA, Thakkar AL. Micelle formation and testosterone solubilization by sodium glycocholate. J Pharm Sci. 1972;61(11): 1757-1761.

6. Rees JA, Collett JH. The dissolution of salicylic acid in micellar solutions of polysorbate 20. J Pharm Pharmacol. 1974;26(12):956-960.

7. Casella R, Williams DA, Jambhekar SS. Solid-state $\beta$-cyclodextrin complexes containing indomethacin, ammonia and water. II. Solubility studies. Int J Pharm. 1998;165:15-22.

8. Trapani G, Latrofa A, Franco M, Lopedota A, Maciocco E, Liso G. Water-soluble salts of amino acid esters of the anaesthetic agent propofol. Int J Pharm. 1998;175(2):195-204.

9. Ali N, Javadzadeh Y, Shadbad MRS, Jalali MB. The effect of type and concentration of vehicles on the dissolution rate of a poorly soluble drug (indomethacin) from liquisolid compacts. J Pharm Pharm Sci. 2005 8(1):18-25.

10. Nokhodchi A, Talari R, Valizadeh H, Jalali MB. An investigation on the solid dispersions of chlordiazepoxide. Int J Biomed Sci. 2007; 3(3):211-216.

11. Seedher N, Kanojia M. Micellar solubilization of some poorly soluble antidiabetic drugs: a technical note. Pharm Sci Technol. 2008;9(2): 431-436.

12. Patil MP, Gaikwad NJ. Preparation and characterization of gliclazidepolyethylene glycol 4000 solid dispersions. Acta Pharm. 2009;59(1): 57-65.

13. Biswal S, Sahoo J, Murthy PN, Giradkar RP, Avari JG. Enhancement of dissolution rate of gliclazide using solid dispersions with polyethylene glycol 6000. AAPS PharmSciTech. 2008;9(2):563-570.

14. Tejal JS, Amin AF, Parikh JR, Parikh RH. Process optimization and characterization of poloxamer solid dispersions of a poorly watersoluble drug. AAPS PharmSciTech. 2007;8(2):E18-E24.

15. Chen Y, Zhang GGZ, Neilly J, Marsh K, Mawhinney D, Sanzgiri YD Enhancing the bioavailability of ABT-963 using solid dispersion containing Pluronic F-68. Int J Pharm. 2004;286(1-2):69-80.

16. Mahmood A, Ahmad M, Sarfraz RM, Usman MU. $\beta$-CD based hydrogel microparticulate system to improve the solubility of acyclovir: optimization through in-vitro, in-vivo and toxicological evaluation. J Drug Deliv Sci Tech. 2016;36:75-88.

17. Sarfraz RM, Ahmad M, Mahmood A, Usman MU, Yaqoob A. Development and evaluation of rosuvastatin calcium based microparticles for solubility enhancement: an in vitro study. Adv Polym Technol. 2015.

18. Bourkaib N, Zhou J, Yao J, Fang Z, Mezghran O. Combination of $\beta$-cyclodextrin inclusion complex and self-microemulsifying drug delivery system for photostability and enhanced oral bioavailability of methotrexate: novel technique. Drug Dev Ind Pharm. 2013;39(6): 918-927.

19. Martin PD, Mitchell PD, Schneck DW. Pharmacodynamic effects and pharmacokinetics of a new HMG-CoA reductase inhibitor, rosuvastatin, after morning or evening administration in healthy volunteers. Br J Clin Pharmacol. 2002;54(5):472-477.

20. Balakumar K, Raghavan CV, Abdu S. Self-nanoemulsifying drug delivery system (SNEDDS) of rosuvastatin calcium: design, formulation, bioavailability and pharmacokinetic evaluation. Colloids Surf B. 2013; 112:337-343.
21. Schachter M. Chemical, pharmacokinetic and pharmacodynamic properties of statins: an update. Fundam Clin Pharmacol. 2005;19(1): $117-125$.

22. Ali L, Ahmad M, Usman M, Yousuf M. Controlled release of highly water-soluble antidepressant from hybrid copolymer poly vinyl alcohol hydrogels. Polym Bull. 2014;71:31-46.

23. Parker WO, Lezzi A. Hydrolysis of sodium-2-acrylamido-2-methylpropane sulfonate copolymers at elevated temperature in aqueous solution via 13C NMR spectroscopy. Polymer. 1993;34:4913-4918.

24. Durmaz S, Okay O. Acrylamide/2-acrylamido-2-methylpropane sulfonic acid sodium salt-based hydrogels: synthesis and characterization. Polymer. 2000;41:3693-3704.

25. Mundargi RC, Rangaswamy V, Aminabhavi TM. Poly (N-vinylcaprolactam-co-methacrylic acid) hydrogel microparticles for oral insulin delivery. J Microencapsul. 2011;28(5):384-394.

26. Sharma CP. Interpolymer complex microparticles based on polymethacrylic acid chitosan for oral insulin delivery. $J$ Appl Polym Sci. 2006;99:506-512.

27. Ying L, Michael S, Park K. Microparticles produced by the hydrogel template method for sustained drug delivery. Int J Pharm. 2014; 461(1-2):258-269.

28. Sarfraz RM, Khan HU, Mahmood A, Ahmad M, Maheen S, Sher M. Formulation and evaluation of mouth disintegrating tablets of atenolol and atorvastatin. Indian J Pharm Sci. 2015;77(1):83-88.

29. Wang ZL. Transmission electron microscopy of shape-controlled nanocrystals and their assemblies. J Phys Chem. 2000;104:1153-1175.

30. Stulzer KH, Tagliari MP, Parize AL, Silva MA, Laranjeira MCM Evaluation of cross-linked chitosan microparticles containing acyclovir obtained by spray-drying. Mater Sci Eng C. 2009;29(2):387-392.

31. Khan SA, Ahmad M, Murtaza G, et al. Formulation of nimesulide floating microparticles using low-viscosity hydroxypropyl methylcellulose. Trop J Pharm Res. 2010;9:293-299.

32. Kumari S, Bhawar GT, Musmade PB, Lewis S. Enhancement of aqueous solubility and oral bioavailability of nelfinavir by complexation with $\beta$-cyclodextrin. Trop J Pharm Res. 2015;14:1333-1340.

33. Peppas NA, editor. Hydrogels in Medicine and Pharmacy. Vol. 1. Boca Raton, FL: CRC Press; 1988.

34. Riekes MK, Tagliari MP, Granada A, Kuminek G, Silva MAS, Stulzer HK. Enhanced solubility and dissolution rate of amiodarone by complexation with $\beta$-cyclodextrin through different methods. Mater Sci Eng C. 2010;30:1008-1013.

35. Chen S, Liu M, Jin S, Wang B. Preparation of ionic-crosslinked chitosan-based gel beads and effect of reaction conditions on drug release behaviors. Int J Pharm. 2008;349(1-2):180-187.

36. Borba PAA, Pinotti M, de Campos CEM, Pezzini BR, Stulzer HK. Sodium alginate as a potential carrier in solid dispersion formulations to enhance dissolution rate and apparent water solubility of BCS II drugs. Carbohydr Polym. 2016;137:350-359.

37. Zhang Y, Yuan LC, Li NG, Heng LJ. Effects of $\beta$-cyclodextrin on the intestinal absorption of berberine hydrochloride, a P-glycoprotein substrate. Int J Biol Macromol. 2013;59:363-371.

38. Sinha S, Ali M, Baboota S, Ahuja A, Kumar A, Ali J. Solid dispersion as an approach for bioavailability enhancement of poorly water-soluble drug ritonavir. AAPS PharmSciTech. 2010;11(2):518-527.

39. Elliott JE, Macdonald M, Nie J, Bowman CN. Structure and swelling of poly (acrylic acid) hydrogels: effect of $\mathrm{pH}$, ionic strength, and dilution on the crosslinked polymer structure. Polymer. 2004;45:1503-1510.

40. Chen $\mathrm{KS}, \mathrm{Ku} \mathrm{YA}$, Lin HR, et al. Preparation and characterization of pH sensitive poly (N-vinyl-2-pyrrolidone/itaconic acid) copolymer hydrogels. Mater Chem Phys. 2005;91:484-489.

41. Atta A. Swelling behaviors of polyelectrolyte hydrogels containing sulfonate groups. Polym Adv Technol. 2002;13:567-576.

42. Shilpi S, Ali M, Baboota S, Ahuja A, Kumar A, Ali J. Solid dispersion as an approach for bioavailability enhancement of poorly water-soluble drug ritonavir. AAPS PharmSciTech. 2010;11(2):518-527. 


\section{Publish your work in this journal}

Drug Design, Development and Therapy is an international, peerreviewed open-access journal that spans the spectrum of drug design and development through to clinical applications. Clinical outcomes, patient safety, and programs for the development and effective, safe, and sustained use of medicines are the features of the journal, which

has also been accepted for indexing on PubMed Central. The manuscript management system is completely online and includes a very quick and fair peer-review system, which is all easy to use. Visit http://www.dovepress.com/testimonials.php to read real quotes from published authors.

Submit your manuscript here: http://www.dovepress.com/drug-design-development-and-therapy-journal 